face. The tongue when protruded pointed slightly to the left. Articulation seemed natural. Hearing normal, but somewhat less acute on the right side. There was complete paralysis of the left fingers and wrist, very limited movements of the elbow, and at the shoulder these were greatly impaired. The left lower extremity was weaker than the right, and although the patient could walk be did so with a limp, and swinging his left leg, as he could not clear the toes from the ground. The mechanical irritability of the muscles, the knee jerk, and the ankle clonus were most marked on the left side. The sensibility of the kkin was everywhere normal, and there was nowhere any muscular wasting.

While under observation the patient suffered from violent paroxyems of lancinating pain in the head, which at times rerdered him nearly delirious. He also was frequently seized with attacks of uncontrollable vomiting, which sometimes continued for days together and prevented his taking nourishment. The twitchings which occurred many times a day without loss of consciousness were also noted. These usually began in the fingers and thumb of the left hand, and consisted of rapid rhythmical movements lasting for a minute or two. These were sometimes confined to the arm alone, and sometimes to the face alone. Occasionally they began in the face, and from there extended to the arm, and down the leg of the same side. They were never observed in the leg alone.

These, briefly stated, are the chief symptoms which this patient presented. Combined with a general consideration of the facts of the case they led Dr. Bennett to arrive at the following conclusions. First, that there was a tumour in the brain; secondly, that this growth involved the cortical substance; thirdly, that it was probably of limited size, as it had destroyed the centres presiding over the hand, and only caused irritation without paralysis of the centres of the leg, face, and eyelids which surround it ; and fourthly, that it was situated in the neighbourhood of the upper third of the fissure of Rolando.

This diagnosis having been made, Dr. Bennett suggested that the tumour be cut down upon and removed. He was all the more encourged to propose such an operation as the sufferings of the patient had become intolerable. All the risks were fairly explained to the man, who cheerfully consented to any procedure which offered any prospects of relief. Accordingly, on Nov. 25th Mr. Godlee trephined the skull, and removed a triangular piece of bone over the region corresponding with the upper part of the fissure of Rolando. The surgical details need not here be entered upon, as these, with the other more precise facts of the case, will be subsequently brought before the profession. It is at present sufficient to say that even after the bone was removed, the dura mater slit up, and the cortex of the brain exposed, no tumour was visible. The ascending frontal convolution, however, seemed to be somewhat distended. An incision about an inch long was made into the grey matter in the direction of the bloodvessels, and a quarter of an inch below the surface a morbid growth was found. This was carefully removed, and proved to be a hard glioma about the size of a walnut. The superficial part of this was distinet from the brain matter and was easily enucleated. The bimorrhage was arrested by means of the galvano-cautery and the wound brought together by sutures.

Since the operation up to the present time (Dec. 15th) it may be said in general terms that the condition of the patient has been satisfactory. At no time has the temperature been above $100^{\circ}$, or the pulse over 90 beats per minute. The patient has throughout been perfectly intelligent, and now is cheerful, and expresses much gratitude at the result of the operation. He has totally lost the lancinating pains in his head, the vomiting, and the convulsions of his limbs; kis appetite is excellent, and all his functions are naturally performed. The state of the wound has given rise to some anxiety, as a hernia formed, consisting for the most part of clot and granular matter, which was shaved off. This caused the flaps in the scalp to gape open, and these have not yet healed. This, however, does not seem to cause the patient any inconvenience. Since the appearance of the hernia cerebri the paresis of the left leg has increased, but bow much this may improve it is at present impossible to conjecture.

We need scarcely observe that the further progress of this man will be watched with the greatest interest by all those who appreciate the important physiological and clinical principles involved in the case.

\section{BRADFORD INFIRMARY.}

TWO CASES OF DOUBLE OÖPHORECTOMY. (Under the care of Dr. RABAGLIATI.)

Fon the following notes we are indebted to Mr. W. J. Spence, house-surgeon.

CASE 1. - Sarah S—, aged twenty-six, married, a slightbuilt, delicate-looking woman, wasadmitted during December, 1882, complaining of a constant pain, which at times became most excruciating, affecting the left iliac region. Prior to admission she had been under the care of several practitioners, and had been in hospital three times. The remedies had been many and varied; a variety of instruments had been worn. all of which increased rather than diminished the pain. Posterior hysterotomy and dilatation of the os had been tried, blisters, baths, and innumerable medicines, but all to no purpose; the patient gradually got worse, until lately life had become, to use her own expression, unbearable. The pain, which increased on deep pressure, commenced six years ago (six months after marriage) with what she says was an inflammation of the bowels. It was at first intermittent, being sometimes free for days together, but of late it had become constant. Menstruation began when she was seventeen years of age, and has continued at irregular intervals ever since. She has never had any children. The sound passed two inches within the cavity of the uterus, causing great pain; there was slight retroflexion.

After a consultation with Mr. Miall, Dr. Rabagliati decided upon removing the ovaries as a last resource. The serious nature of the operation, with its results, was plainly put before the patient, but she urgently pressed for the operation, preferring it with all its risks to the suffering she was undergoing. The operation was performed on Aug. 10th with striet antiseptic precautions. The ovaries, together with their appendages, were removed through an abdominal in cision from three to four inches in length; silkworm gut was used to secure the pedicles. Both ovaries were found to be enlarged, cystic, and adherent to the surrounding parts. On section they appeared injected, but there was no sign of suppuration. The Fallopian tubes were greatly dilated.

The wound healed by first intention and the patient made a good recovery. She has been seen at frequent intervals since the operation and expresses herself as quite a new woman, the old pain having entirely disappeared.

CASE 2 -Elizabeth L-, housewife, aged twenty-eight, was admitted on March 29th, 1884, complaining of severe pain in the right iliac region. The patient stated that menstruation commenced when she was sixteen years of age, and had continued at regular intervals ever since. The menstrual discharge was normal in quantity and appearance. She was married three years ago and delivered of a female child eleven months later. The child was brought up by hand and is alive and healthy. The labour was tedicus, lasting twenty-three hours after rupture of membranes. She made a good recovery, being up and attending to ber household duties at the end of a fortnight. The catamenia appeared two months afterwards. She has since been regular. About three or four months after the child was born she began to be troubled with pain in the region of the right ovary, it was, at first, intermittent and slight in character, but gradually increased in severity ; it became constant and extended to the back and down the thigh of the affected side. Of late it had become almost unbearable. Her medical attendant, Mr. Miall, tried all the usual remedies, but without any relief

After a consultation with Dr. Rabagliati, and at the patient's urgent request, it was decided to remove the ovaries, and for this purpose she was removed to the infirmary. Upon admission the pain was found to be located in the right iliac region and was increased upon deep pressure. The uterus was normal in position and appearance and the sound entered nearly two iuches. The operation was performed under chloroform administered on a towel at 9 A.M. on April 9 th. Strict antiseptic precautions were observed. The ovaries and their appendages were removed through a median abdominal incision three to four inches in length. Silkworm gut was used for the pedicle, as in the last case. The wound was closed by deep chromic catgut sutures, which included the peritoneum as well as the remainder of the structures forming the abdominal wall. $B:$ fore the chromic sutures were tied the cut edges of the neriton eum wer brought together by fine catgut sutures. Some superficial B B 2 
ones were also used to bring the skin into more accurate apposition. The right ovary was found to be cystic and the corresponding Fallopian tube somewhat constricted. The left ovary was also cystic, but the Fallopian tube appeared normal. During removal of the left ovary a large superficial cyst was ruptured.

There was slight sickness during and immediately after the operation, but none afterwards. For the first twentyfour hours the patient was allowed nothing but ice. On the second day a little milk diluted with water was given, On the fourth day there was slight appearance of catamenia, which lasted three days. The case ran a most favourable course; the temperature was never higher than $100.8^{\circ}$, the wound healed by first intention, and was quite sound on the ninth day. The patient was discharged cured at the end of the month. The patient has been seen at frequent intervals, and expresses herself as quite relieved. The old pain has entirely disappeared.

\section{SOOREE CHARITABLE DISPENSARY.}

CASE OF LIVER ABSCESS TREATED WITI FREE INCISION AND DRAINAGE; RECOVERY.

(Under the care of Dr. G. C. RoY.)

W. W-, aged about thirty years, a Mahommedan constable, presented himself for treatment on June 4th, 1882 . He was very emaciated, and so weak that he had to be lifted from his bed. He was subject to malarious fever off and on. About three months before admission he had fever of low remittent type, followed three days after by pain over the liver, which had continued ever since. $\mathrm{He}$ was habitually addicted to spirituous liquor.

On admiasion his pulse was very weak and quick ; tongue clean; bowels confined; appetite poor. The liver dulness extended to one inch below the costal cartilages, but at the side there was a uniform bulging with fluctuation and pain on pressure. No jaundice.

An incision about an inch in length was made on the seventh intercostal space in the axillary line under carbolic spray, and the cavity of the abscess was reached. About sixteen ounces of pus mixed with blood were evacuated; a drainage-tube eight inches in length was introduced and covered with a padding of cotton saturated with corrosive sublimate lotion and tied, and the whole secured by a body bandage.

The discharge continued free, being of the same colour and consistence. There was no accumulation of mat, er even when the cavity was sucked out by the aspirator. Weak carbolic lotion was injected for two days, but it produced strangury and sy mptoms of carbolic poison. The discharge gradually got less, and as the cavity contracted the drainage-tube was shortened, till on the $25 \mathrm{th}$ it came out altogether. On that date there was hardly any discharge, still he was kept under observation for four days, and discharged on the 30th with the liver reduced to its normal size; appetite was good, and the patient was then going about the hospital.

\section{A CASE OF IMPERFORATE ANUS AND PREPUCE.}

(Under the care of Dr. G. C. RoY.)

A child was brought three days after birth with absence of anal aperture. It was said that it had not passed water or any stool. The abdomen was swollen, the breathing was laboured, and its general condition was low.

In front of the coccy $x$ and in the median line there was a slight depression, over which an incision was made and dissected down to the extent of one inch, but no dilated cloaca was found. A coil of intestine was felt, and as the child strained it was hooked down by a bent probe and opened, when meconium flowed out freely. There was closure of the prepuce producing phimosis, which was also circumcised. As after operation the child's condition seemed critical, no further manipulation was atternpted, but it was put to the breast, and the mother was asked to come the next day. Nothing more was heard of it for ten days or a fortnight, when the mother returned with the child well developed for further relief, as the artificial opening was contracting and a faecal sinus had formed in the scrotum. On probing the latter it was found to pass under the skin and communicate with the former. The sinus was laid open in two operations throughout its entire length, and at the lower part the bowels were found to be superficial and adherent to the skin. This opening was situated in front of the previous one, and was continuous with it. It had formed for itself a sort of mucous lining. The bowels continued to be dis. charging through this without any impediment, and the mother was asked to reappear after a month if there was any tendency to closure. The child was brought afterwards for observation, looking healthy and with no tendency to con traction of the artificial anus.

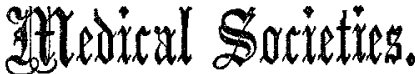

\section{PATHOLOGICAL SOCIETY OF LONDON.}

\section{Intestinal Obstruction produced by Gall-stones.-Gunshot \\ Injury of Brain. -Sympathetic System in Diabetes.}

AN ordinary meeting of this Society was held on Tuesday last, Mr. J. Whitaker Hulke, F.R.S., President, in the chair.

Dr. PAYNE read the report of the Morbid Growths Committee on Drs. Lanchester and Hobson's case of Caseous Pneumonia. In some parts of the lesion, tubercle, with wellmarked giant cells, were to be seen; and the lymphatic vessels contained much grauular matter. The remarkable uniformity of the changes throughout the lungs was evidence of the age of the various parts being the same. The fibrous exudation in the alveoli, which bad undergone fatty and granular change, as well as the fibrinous nature of the morbid products, pointed to the conclusion that the case was one of acute lobar fibrinous pneumonia, which had ended in caseous degeneration, and had been accompanied by acute tuberculosis. Usually caseous changes were the result of lobular catarrhal processes, and so this case was very rare. Possibly Addison had described the disease, but Cornil certainly had, under the term "pneumonie caséeuse lobaire," and as a secondary accompaniment of tuberculosis. Whether the pneumonia or tuberculosis were primary it would be difficult to decide.

Dr. S. WILKs showed, for Mr. Wilks of Salisbury, some specimens of Gall-stones which had caused intestinal obstruction. The patient was a single woman, aged fortytwo, who suffered for seventeen days from obstruction of the bowels. She was first seen on Nov. 5th, 1884, when constipation had lasted two days; there was not a great distension of the abdomen, but some sickness was followed later bv stercoraceous vomiting, and the symptoms lasted until Sov. 21st. Then an enema was given and brought away a large stone which was floating in the bed-pan; on the 22nd a second stone came away embedded in fæcal matter. Reference was made to a drawing in Frerich's work which bore on the case. The bigger stone had a concave facet and weighed 250 grains; it measured $1 \frac{1}{2}$ in. by $\frac{1}{8}$ in., and was 31 in. in circumference. The other stone weighed 130 grains, and measured $\frac{3}{x}$ in. in length. In the Patho logical Transactions similar cases had been reported by $\mathrm{Dr}$. H. Fagge, and Ur. Murchison believed that the stones formed in the gall-biadder and then made their way directly into the intestine. In this case there was no previous history of gall-stone or jaundice. It was generally believed that the cause of obstruction was outside the intestine, axd so the present case was very exceptional.Mr. HLLKE asked at what part of the intestines it was supposed that the stone had lodged.-Mr. JoHN WooD referred to a case on which he operated some months ago. There was a painful tumour about the gall-bladder, and adhesions existed between the gall-bladder and the wall of the abdomen. Careful dissection was made, and then thickened tissue connected with an abscess containing two gall-stones of the size of a small nutmeg was detected in contact with and adherent to the hepatic flexure of the colon. He had, in fact, intercepted the passage of the gall-stones from the gall-bladder to the colon.-Mr. HuLKE referred to a case in which a large round knob was felt in the rectum, and had acted like the ball of an ordinary valve causing obstruction, which was easily relieved. - Mr. ClEMENT LUCAs said that the stone could not have obstructed the colon.-Mr. F. TREves thought every possible evidence was in favour of the view of Dr. Wilks, that gall-stones ulcerated directly into the intestine. He had collected forty-eight cases of obstruction, due to gall. stones. Of these thirty-two were to be found in a paper by Leichtenstern. In the majority of cases direct evidence of ulceration between the gall-bladder and duodenum was to be obtained. Stones which measured three inches in cir- 